
ISSN : 2615-1995, E-ISSN : 2615-0654

J. Madani., Vol. 3, No. 1, Maret 2020 (56 - 65)

(C)2018 Lembaga Kajian Demokrasi

\title{
Current Ratio (CR) dan Debt to Asset Ratio (DAR) Terhadap Return on Asset (ROA) Pada PT Indocement Tunggal Prakarsa Tbk Periode 2009-2018
}

\author{
Diana Riyana Harjayanti \\ Fakultas Ekonomi, Universitas Pamulang \\ dharjayanti@yahoo.com \\ Puput Pujiati \\ Fakultas Ekonomi, Universitas Pamulang \\ puputpujiati455@gmail.com
}

\begin{abstract}
Abstrak
Untuk memastikan kondisi keuangan suatu perusahaan maka perlu dilakukan pengukuran dari rasio yang mewakili likuiditas, solvabilitas dan provitabilitas. Sehingga dalam penelitian ini dilakukan pengamatan terhadap rasio Current Ratio, Debt to Asset Ratio, Return On Asset pada PT Indocement Tbk. sebagai salah satu pabrik semen terbesar di Indonesia. Data yan digunakan dalam penelitian adalah data sekunder dari laporan keuangan perusahaan dari tahun 2009 -2018. Tahapan pengolahan data yang dilakukan dilakukan adalah memastikan semua data memenuhi standard uji asumsi klasik, agar selanjutnya dapat dilakukan tahapan pengolahan data untuk melihat pengaruh variabel bebas yaitu Current Ratio dan Debt to Asset Ratio terhadap variabel terikat yaitu Return On Asset melalui uji regresi linier berganda, uji koefisien determinasi $R$, uji $t$, uji F. Dari hasil uji t maka Current Ratio berpengaruh secara partial terhadap Return On Asset, namun Debt to Asset Ratio tidak berpengaruh secara partial terhadap Retun On Asset. Sedangkan dari hasil uji F maka Current Ratio dan Debt to Asset Ratio berpengaruh secara bersamaan terhadap Return on Asset.
\end{abstract}

Kata Kunci : Current Ratio, Debt to Asset Ratio, Return on Asset.

\begin{abstract}
It is necessary to measure ratios that represent liquidity, solvability and profitability from one company. Related to this research use Current Ratio, Debt to Asset Ratio, Return on Asset Ratio at PT Indocement Tunggal Prakarsa Tbk. As one of largest cement factories in Indonesia. It is necessary to measure ratios that represent liquidity, solvability and profitability from one company. Related to this research use ratio of Current Ratio, Debt to Asset Ratio, Return on Assets at PT Indocement Tbk. as one of the largest cement factories in Indonesia. The data used in this study are secondary data from the company's 2009-2020 financial statements. Data processing stages are carried out by ensuring all data meet the classic assumption test, so that further stages are to measure influence of independent variabels : Current Ratio and Debt to Asset Ratio to dependent variabel : Return On Asset with multiple linear regression test, coefficient $R$ determinant test, $t$ test, $F$ test. In addition, the results of the t test, the Current Ratio is partial influence to Return On Assets, but the Debt to Asset Ratio is not partial influence on Return On Assets. While from the results of the F test the Current Ratio and the Debt to Asset Ratio simultaneously influence to Return on Assets.
\end{abstract}

Keywords : Current Ratio, Debt to Asset Ratio, Return on Assets. 


\section{PENDAHULUAN}

Berbagai analisa akan dilakukan untuk memastikan apakah perusahan mempunyai kinerja yang baik dalam periode tersebut dan sebagai dasar penetapan target acuan untuk meningkatkan kinerja di periode selanjutnya. Salah satu analisa yang dilakukan untuk mengukur kinerja adalah dengan melakukan pengukuran beberapa rasio keuangan dalam beberapa periode terakhir sehingga dapat dianalisa trend kinerja beserta pengaruh rasio tersebut terhadap kinerja perusahaan. Dalam penelitian ini dilakukan pengamatan terhadap rasio yang dianggap mewakili kinerja pos neraca aktiva, passiva dan laporan laba rugi dari suatu laporan keuangan. Dan mewakili indikator dari rasio provitabilitas, likuditas dan solvabilitas.

Salah satu indikator kinerja suatu perusahaan adalah melalui besarnya laba yang dihasilkan sehingga perlu dilakukan pengukuran terhadap rasio profitabilitas. Melalu rasio profitabilitas maka dapat diukur tingkat efektifitas perusahaan dalam mengelola aset dan sumber daya yang ada untuk menghasilkan keuntungan.

Munawir (2012:89), menjelaskan bahwa "Return on Asset adalah salah satu bentuk dari rasio profitabilitas yang dimaksudkan untuk dapat mengukur kemampuan perusahaan dengan keseluruhan dana yang ditanamkan dalam aktiva yang digunakan untuk operasinya perusahaan untuk menghasilkan keuntungan". Sehingga dengan rasio Return on Asset dapat diketahui apakah perusahaan telah dengan baik mengelola aset yang dimiliki untuk menghasilkan laba bagi perusahaan.

Perusahaan dalam menghasilkan laba bagi perusahan, banyak yang meggunakan dana pihak ketiga berupa pinjaman, baik pinjaman jangka pendek maupun pinjaman jangka panjang. Sehingga diperlukan indikator yang mewakili rasio likuiditas dan rasio solvabilitas untuk mengukur tingkat kesehatan dan kinerja keuangan perusahaan. Karena kedua rasio tersebut saling terkait. Rasio likuditas adalah rasio yang dapat memberikan gambaran kemampuan liquid perusahaan dalam memenuhi kewajiban hutangnya yang akan jatuh tempo dalam waktu dekat. Sedangkan untuk mengukur kemampuan perusahaan dalam memenuhi kewajiban hutang dengan menggunakan aset yang dimiliki maka dapat menggunakan rasio solvabilitas.

Rasio likuditas yang digunakan dalam penelitian ini adalah Current Ratio. Menurut Agnes Sawir (2003:8), menjelaskan bahwa "Current Ratio merupakan ukuran yang paling umum digunakan untuk mengetahui kesanggupan memenuhi kewajiban jangka pendek, karena rasio ini menunjukan seberapa jauh tuntutan dari kreditor jangka pendek dipenuhi oleh aktiva yang diperkirakan menjadi uang tunai dalam periode yang sama dengan jatuh tempo utang". Sedangkan yang mewakili rasio solvabilitas dalam penelitiaan ini adalah Debt to Asset Ratio. Menurut Kasmir (2014:156). Menjelasakan "Debt to Asset Ratio merupakan rasio utang yang digunakan untuk mengukur perbandingan antara total utang dengan total aktiva. Dengan kata lain, seberapa besar aktiva perusahaan dibiayai oleh utang atau seberapa besar utang perusahaan berpengaruh terhadap pengelolaan aktiva".

PT Indocement Tunggal Prakarsa Tbk sebagai salah satu perusahaan yang memproduksi semen terbesar di Indonesia dengan merk yang dikenal di masyarakat adalah semen Tiga Roda. Produk yang dihasilkan selain berupa semen, juga dihasilkan beton siap pakai serta mengelola tambang agregat dan tras dengan kapasitas produksi terpasang adalah 75 juta Ton. PT Indocement Tunggal Prakarsa Tbk sudah beroperasi sejak 4 Agustus 1975. Untuk memenuhi kebutuhan konsumen terutama dalam bidang properti maka PT Indocement Tunggal Prakarsa Tbk terus menambah jumlah pabrik menjadi 12 lokasi yang sebagian besar berada di pulau Jawa.

Tabel 1. Kondisi Current Ratio, Debt to Asset Ratio dan
Return on Asset pada PT. Indocement Tunggal Prakarsa Tbk
\begin{tabular}{|c|c|c|c|}
\hline Tahun & $\begin{array}{c}\text { Current Ratio } \\
\text { (dalam kali) }\end{array}$ & $\begin{array}{c}\text { Debt to Asset } \\
\text { Ratio (dalam \%) }\end{array}$ & $\begin{array}{c}\text { Return On Asset } \\
\text { (dalam \%) }\end{array}$ \\
\hline 2009 & 3.00 & 19.37 & 20.69 \\
\hline 2010 & 5.55 & 14.63 & 21.01 \\
\hline 2011 & 6.98 & 13.32 & 19.84 \\
\hline 2012 & 6.03 & 14.66 & 20.93 \\
\hline 2013 & 6.15 & 13.64 & 18.84 \\
\hline 2014 & 4.93 & 14.19 & 18.26 \\
\hline
\end{tabular}




\begin{tabular}{|c|c|c|c|}
\hline 2015 & 4.89 & 13.65 & 15.76 \\
\hline 2016 & 4.53 & 13.31 & 12.84 \\
\hline 2017 & 3.70 & 14.92 & 6.44 \\
\hline 2018 & 3.14 & 16.43 & 4.12 \\
\hline Rata-rata & 4.89 & 14.81 & 15.87 \\
\hline \multicolumn{4}{|c|}{ Sumber: Annual Report data diolah } \\
\hline
\end{tabular}

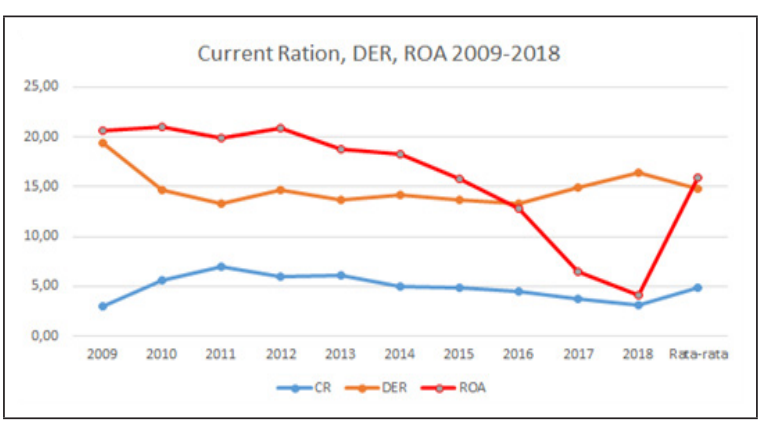

Gambar 1. Trend Grafik Current Ratio, DER, ROA Tahun 2009-2018

Berdasarkan latar belakang yang disampaikan di atas maka permasalahan yang akan dibahas dalam penelitian ini adalah mencari pengaruh Current Ratio dan Debt to Asser Ratio terhadap Return On Asset pada PT. Indocement Tunggal Prakarsa Tbk. periode tahun 2009-2018. Sebagai gambaran yang menjelaskan hubungan antara variabel yang diteliti digambarkan dalam kerangka berpikir dibawah ini:

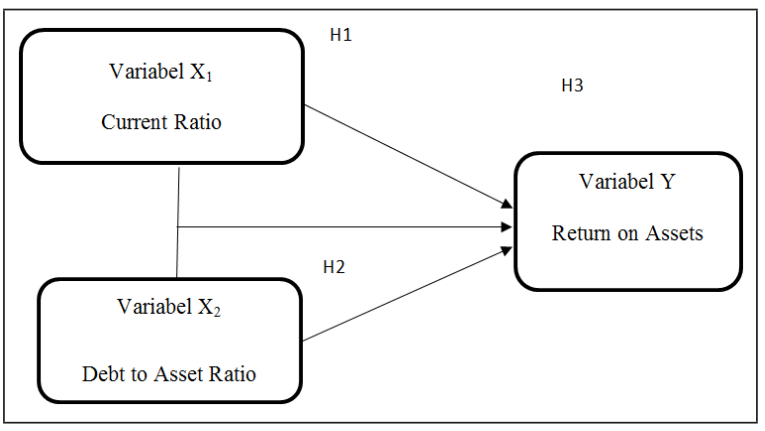

Gambar 2. Kerangka Berpikir

Hipotesis yang diajukan dalam penelitian ini dapat dirumuskan sebagai berikut:

Ho: $\beta_{1}=0$ : tidak ada pengaruh antara Current Ratio terhadap Return on Asset pada PT Indocement Tunggal Prakarsa Tbk.

Ha: $\beta_{1} \neq 0$ : ada pengaruh antara Current Ratio terhadap Return on Asset pada PT Indocement Tunggal Prakarsa Tbk.

Ho: $\beta_{2}=0$ : tidak ada pengaruh antara Debt to Asset Ratio terhadap Return on Asset pada PT Indocement Tunggal Prakarsa, Tbk.

Ha: $\beta_{2} \neq 0$ : ada pengaruh antara Debt to
Asset Ratio terhadap Return on Asset pada PT Indocement Tunggal Prakarsa, Tbk.

Ho: $\beta_{1}=\beta_{2}=0$ : tidak ada pengaruh antara Current Ratio dan Debt to Asset Ratio terhadap Return on Asset pada PT Indocement Tunggal Prakarsa, Tbk.

Ha: $\beta_{1} \neq \beta_{2} \neq 0$ : ada pengaruh antara Current Ratio dan Debt to Asset Ratio terhadap Return On Asset pada PT Indocement Tunggal Prakarsa, Tbk.

\section{METODE}

\section{Metode Pengumpulan Data}

Studi Kepustakaan

Studi pustaka adalah teknik pengambilan data dari teori terdahulu yang bersumber dari buku atau literature, jurnal, artikel yang berhubungan dengan tema yang sedang diteliti.

\section{Riset Data Sekunder}

Data sekunder merupakan data yang diperoleh secara tidak langsung atau data pimer yang diolah lebih lanjut agar dapat dilakukan analisa. Contohnya melalui data laporan keuangan perusahaan yang telah dipublikasikan.

\section{Metode Analisa Data}

Pengumpulan data berasal dari laporan keuangan PT Indocement Tunggal Prakarsa Tbk dengan periode 2009-2018, maka data tersebut akan diolah dengan menggunakan salah satu software statistika yaitu Microsoft Excel dan SPSS for Windows versi 20. Berikut analisis data yang digunakan dalam penelitian ini:

\section{Current Ratio}

$$
C R=\frac{\text { Aktiva Lancar }}{\text { Hutang Lancar }} \times 100 \%
$$

Debt to Asset Ratio

$$
\text { DAR }=\frac{\text { Total Hutang }}{\text { Total Aktiva }} \times 100 \%
$$

\section{Return on Assets}

ROA $=\frac{\text { Laba Bersih }}{\text { Total Aktiva }} \times 100 \%$ 


\section{Operasional Variabel}

Operasional variabel merupakan unsur dari suatu penelitian yang akan dilakukan pengukuran yang terdiri dari variabel bebas maupun variabel terikat. Menurut Sugiyono (2016: 38) "Variabel penelitian adalah suatu atribut atau sifat atau nilai dari orang, objek atau kegiatan yang mempunyai variasi tertentu yang ditetapkan oleh peneliti untuk dipelajari dan kemudian ditarik kesimpulannya". Opersional variabel adalah suatu unsur penelitian bagaimana cara mengukur suatu variabel, baik variabel independen dan variabel dependen. Dari kedua variabel tersebut maka akan dikembangkan menjadi suatu hipotesa sebagai bahan untuk dilakukan analisa lebih lanjut.

\section{Variabel Independen (Variabel X)}

Disebut variabel independen atau variabel bebas karena variabel tersebut bisa menggunakan angka yang bebas/berapa saja dan dapat mempengaruhi variabel dependen atau variabel terikat. Dalam penelitian ini yang termasuk dalam variabel bebas adalah:

\section{Current Ratio $\left(\mathrm{X}_{1}\right)$}

Current Ratio merupakan rasio yang digunakan untuk mengetahui kemampuan perusahaan menggunakan aktiva lancar dalam memenuhi kewajiban jangka pendeknya dalam suatu periode.

\section{Debt to Asset Ratio (X2)}

Debt to Assets Ratio merupakan rasio yang digunakan untuk mengetahui keseluruhan asset perusahaan yang dibiayai oleh hutang.

\section{Variabel Dependen (Variabel Y)}

Disebut variabel dependen atau variabel terikat karena variabel tersebut tergantung atau dipengaruhi oleh varibel independe atau variabel terikat. Dan dalam penelitian ini yang menjadi variabel terikat adalah Return on Assets (Y).

Agar diperoleh gambaran yang lebih jelas dari masing-masing variabel dalam penelitian ini, maka berikut dijabarkan dalam tabel dibawah ini:

\begin{tabular}{|c|c|c|l|c|}
\hline \multicolumn{1}{|c|}{ Tabel 2. Operasional Variabel Penelitian } \\
\hline Jenis & Variabel & Dimensi & \multicolumn{1}{c|}{ Indikator } & Skala \\
\hline $\begin{array}{c}\text { Variabel Bebas } \\
\text { (Independen) }\end{array}$ & $X$ & $\begin{array}{c}\text { Current } \\
\text { Ratio (CR) }\end{array}$ & $\begin{array}{l}\text { 1. Aktiva Lancar } \\
\text { 2. Hutang } \\
\text { Lancar }\end{array}$ & Rasio (kali) \\
\cline { 2 - 5 } & $\begin{array}{c}\text { Debt to } \\
\text { Asset Ratio } \\
\text { (DAR) }\end{array}$ & $\begin{array}{l}\text { 1. Total Hutang } \\
\text { 2. Total Aktiva }\end{array}$ & Rasio (\%) \\
\hline $\begin{array}{c}\text { Variabel Terikat } \\
\text { (Dependen) }\end{array}$ & $Y$ & $\begin{array}{c}\text { Return On } \\
\text { Asset (ROA) }\end{array}$ & $\begin{array}{l}\text { 1. Laba Bersih } \\
\text { 2. Total Aktiva }\end{array}$ & Rasio (\%) \\
\hline
\end{tabular}

\section{Uji Data}

Selanjutnya dilakukan Uji Asumsi Klasik. Dalam penelitian ini terdapat 4 (empat) uji asumsi klasik, yaitu: uji normalitas, uji multikoliniearitas, uji heteroskedastisitas, dan uji autokorelasi. Setelah memenuhi uji asumsi klasik, maka dilakukan Uji Hipotesis adalah analisis regresi linear berganda, uji koefisien determinasi (R2), uji parsial (Uji-T), dan uji simultan (Uji-F).

\section{HASIL dan PEMBAHASAN}

\section{Analisis Statistik Deskriptif}

Menurut Sugiyono (2014: 238) menerangkan mengenai "Statistik Deskritif adalah statistik yang digunakan untuk menganalisi data dengan cara mendeskripsikan atau menggambarkan data yang telah terkumpul sebagaimana adanya tanpa maksud membuat kesimpulan yang berlaku umu atau generalisasi”.

Yang dapat digambarkan dari statistik deskritif adalah jumlah data yang diteliti, nilai minimum dan maksimum dari data tersebut, nilai rata-rata dan standard deviasi dari masingmasing variabel yang diteliti. Pada tabel dibawah ini adalah hasil uji statitik deskritif yang dilakukan dengan menggunakan SPSS 20 disajikan dalam tabel 3 dibawah ini:

\begin{tabular}{|c|c|c|c|c|c|}
\hline \multicolumn{7}{c|}{ Tabel 3. Descriptive Statistics } \\
\hline & N & Minimum & Maximum & Mean & $\begin{array}{c}\text { Std. } \\
\text { Deviation }\end{array}$ \\
\hline CR & 10 & 314.00 & 698.00 & 510.0344 & 121.93814 \\
\hline DAR & 10 & 13.31 & 28.39 & 15.8844 & 4.79498 \\
\hline ROA & 10 & 4.12 & 21.01 & 15.3378 & 6.28439 \\
\hline $\begin{array}{c}\text { Valid N } \\
\text { (listwise) }\end{array}$ & 10 & & & & \\
\hline \multicolumn{7}{|c|c|}{} & & \multicolumn{5}{c|}{ Sumber: Output SPSS 20 } \\
\hline
\end{tabular}

Berdasarkan dari tabel 3 dapat diberikan gambaran bahwa uji statistik deskritif menggunakan 10 data penelitian, dan nilai minimum dari data 
Current Ratio (CR) yang diteliti adalah 314,00 dan nilai maksimum adalah 698,00 dengan nilai ratarata yang diwakili oleh nilai mean adalah 510.0344 dan standar deviasi sebesar 121.93814. Untuk variabel Debt to Asset Ratio (DAR) memiliki nilai yang terkecil atau minimum 13.31 dan nilai tertinggi atau maksimum adalah 28.39 , dengan nilai rata-rata yang diwakili oleh nilai mean sebesar 15.8844 dengan standar deviasi sebesar 4.79498. Dan Return On Asset (ROA) sebagai variabel terikat memiliki nilai yang terkecil atau minimum 4.12 dan nilai tertinggi atau maksimum adalah 21.01, dengan nilai rata-rata yang diwakili oleh nilai mean sebesar memiliki rata-rata sebesar 15.3378 dengan standar deviasi sebesar 6.28439.

\section{Uji Asumsi Klasik}

Uji asumsi klasik adalah pengujian awal yang dilakukan untuk memastikan bahwa model regresi yang digunakan telah memenuhi beberapa syarat pengujian statistik agar dihasilkan estimasi yang akurat dari uji regresi linier yang dilakukan. Berikut akan dijelaskan beberapa uji asumsi klasik yang telah dilakukan.

\section{Uji Normalitas}

Uji normalitas dilakukan untuk memastikan bahwa model regresi yan dihasilkan memiliki nilai residual yang terdistribusi normal. Hal ini dapat terlihat dari distribusi pada grafik P-P Plot dihawah ini yang diolah dengan menggunakan aplikasi SPP versi 2.0.

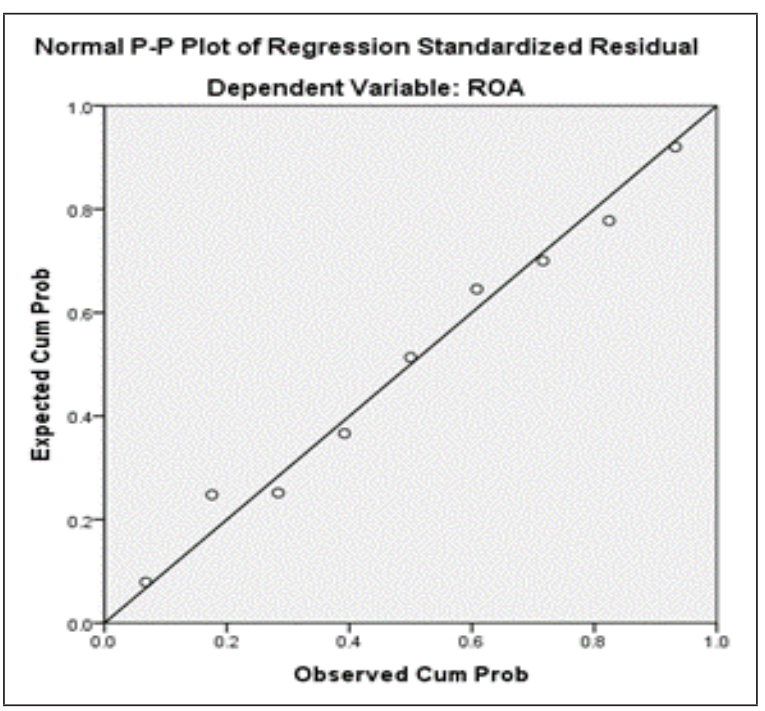

Gambar 3. Grafik P-P Plot
Dari gambar di atas terlihat bahwa titik yang dihasilkan menyebar disekitar maka menunjukan bahwa model regresi yang digunakan memenuhi asumsi normal. Selain melihat grafik yang dihasilkan melalui uji probability plot maka juga dilakukan uji Kolmogrov-Smirnov yang dilakukan dengan membandingkan nilai (Asymp. Sig 2-tailed) sebesar 0.1000 lebih besar dari sig 0.05 pada tabel 4 dibawah ini sehingga dapat disimpulkan data yang diteliti terdistribusi dengan normal.

\begin{tabular}{|l|l|r|}
\hline \multicolumn{2}{|c|}{ Tabel 4. One-Sample Kolmogorov-Smirnov } \\
\hline \multicolumn{2}{|c|}{ One-Sample Kolmogorov-Smirnov Test } \\
\hline N & & $\begin{array}{c}\text { Unstandardized } \\
\text { Residual }\end{array}$ \\
\hline Normal Parameters ${ }^{\text {a,b }}$ & & -1.0726837 \\
\hline \multirow{2}{*}{ Most Extreme Differences } & Mean & 3.18797227 \\
\cline { 2 - 4 } & Std. Deviation & .117 \\
\hline & Absolute & .117 \\
\cline { 2 - 4 } & Positive & -.102 \\
\cline { 2 - 3 } & Negative & .351 \\
\hline Kolmogorov-Smirnov Z & & 1.000 \\
\hline Asymp. Sig. (2-tailed) & & \\
\hline $\begin{array}{l}\text { a. Test distribution is Normal. } \\
\text { b. Calculated from data. }\end{array}$ & & \\
\hline & & \multicolumn{2}{|c|}{ Sumber: 0utput SPSS 20} \\
\hline
\end{tabular}

\section{Uji Multikolinearitas}

Karena variabel independen yang digunakan adalah dua sehingga dikuatirkan antara keduanya memiliki hubungan korelasi yang sangat kuat sehingga dapat menyebabkan informasi yang dihasilkan sangat mirip dan tidak terdapat diketahui pengaruh dari kedua variabel independen tersebut maka dilakukan uji Multikolinearitas. Data yang dilakukan penelitian dapat dikatakan bebas dari Multikolinearitas jika nilai Tolerance dan VIF masing-masing variabel independen memenuhi nilai Tolerance $>0,10$ dan nilai VIF $<10$.

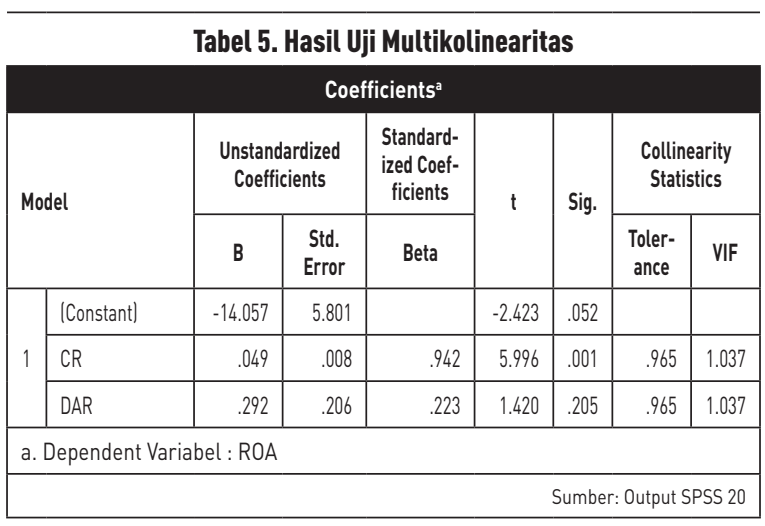


Berdasarkan data uji Multikolinearitas pada tabel 5 maka hasil perhitungan nilai Tolerance yang dihasilkan dari variabel Current Ratio adalah 0.965 sedangkan Debt to Asset Ratio adalah 0.965 sehingga nilai Tolerance yang dihasilkan adalah lebih dari 0,10. Sedangkan dari hasil perhitungan nilai VIF juga dihasilkan nilai VIF dari variabel Current Ratio adalah 1.037 sedangkan Debt to Asset Ratio adalah 1.037 sehingga nilai VIF yang dihasilkan tidak lebih dari 10. Maka dari nilai indikator keduanya dapat disimpulkan tidak terjadi multikolinearitas antar sehingga juga menunjukkan hal serupa yaitu tidak adanya nilai VIF dari variabel independen yang memiliki nilai lebih dari 10, dengan nilai VIF masing-masing variabel independen sebesar 1,037. Merujuk hasil perhitungan nilai Tolerance dan VIF tersebut dapat disimpulkan bahwa tidak ada multikolinearitas antar variabel independen dalam model regresi

\section{Uji Heteroskedastisitas}

Pengujian heteroskedastisitas dilakukan untuk memastikan adanya ketidaksamaan variasi dari antar data yang sedang dilakukan penelitian. Salah satu caranya adalah dengan mengamati pola gambar scatterplot pada gambar 4 dibawah ini. Titik-titik yang terdapat pada gambar menyebar di atas dan dibawah titik 0 sehingga dapat disimpulkan tidak terjadi masalah heteroskedastisitas.

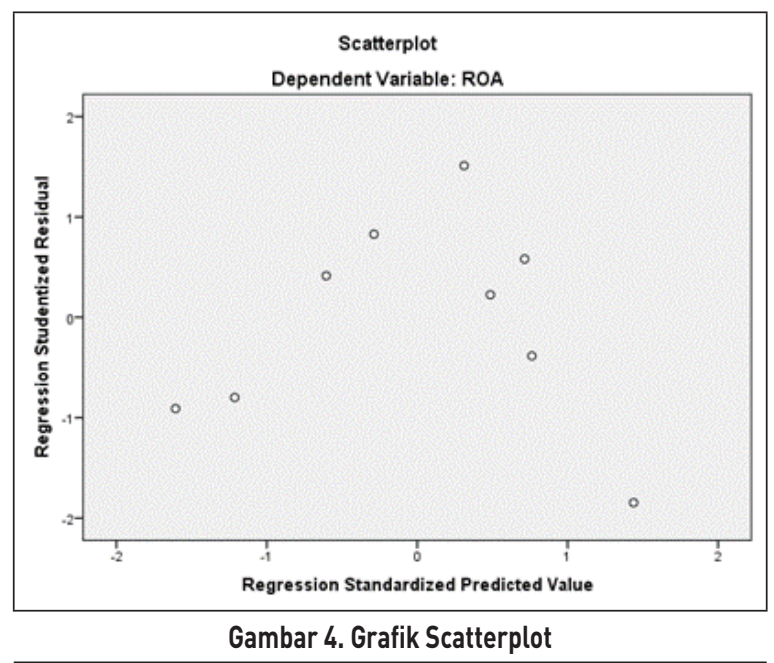

\section{Uji Autokorelasi}

Uji autokorelasi adalah pengujian yang dilakukan untuk memastikan apakah dalam model regresi linier terdapat korelasi variabel antara model prediksi dan periode waktu. Pengujian autokorelasi ddilakukan dengan uji Durbin Watson seperti yang disajikan pada tabel 6 dibawah ini.

\begin{tabular}{|c|c|c|c|c|c|}
\hline \multicolumn{6}{|c|}{ Tabel 6. Hasil Uji Autokorelasi } \\
\hline \multicolumn{6}{|c|}{ Model Summary } \\
\hline Model & $\mathbf{R}$ & R Square & $\begin{array}{l}\text { Adjusted } \\
\text { R Square }\end{array}$ & $\begin{array}{l}\text { Std. Error } \\
\text { of the } \\
\text { Estimate }\end{array}$ & $\begin{array}{l}\text { Durbin- } \\
\text { Watson }\end{array}$ \\
\hline 1 & $.926 a$ & .857 & .810 & 2.74157 & 2.393 \\
\hline \multicolumn{6}{|c|}{ a. Predictors: (Constant), DAR, CR } \\
\hline \multicolumn{6}{|c|}{ b. Dependent Variabel: ROA } \\
\hline \multicolumn{6}{|c|}{ Sumber: Output SPSS 20} \\
\hline
\end{tabular}

Tabel Durbin Watson adalah tabel pembanding dalam uji autokorelasi. Berdasarkan tabel 6 di atas, nilai Durbin Watson sebesar 1.699 pembanding menggunakan nilai signifikansi $5 \%$, jumlah sampel $(\mathrm{n})=9$, jumlah variabel independen $2(\mathrm{k}=2)$, maka di tabel Durbin Watson akan didapat nilai DU sebesar 1.6413. Sehingga dapat disimpulkan tidak terdapat autokorelasi karena nilai (DW) 2.393 lebih besar dari batas atas (DU) 1.6413 dan $4-(\mathrm{DW}) 2.393=1,700$ lebih besar dari (DU) 1.6413, maka dapat disimpulkan bahwa tidak terdapat autokorelasi.

\section{Analisis Regresi Linear Berganda}

Dilakukan uji regresi linier berganda karena variabel independen yang digunakan dalam penelitian ini terdiri dari dua variabel. Melalui uji regresi linier berganda dapat diketahui berapa besar pengaruh masing-masing variabel independen $(\mathrm{X})$ terhadap variabel dependen $(\mathrm{Y})$.

\begin{tabular}{|c|c|c|c|c|}
\hline \multicolumn{5}{|c|}{ Tabel 7. Hasil Analisis Regresi Linear Berganda } \\
\hline \multicolumn{5}{|c|}{ Coefficients $^{\mathrm{a}}$} \\
\hline \multirow{2}{*}{\multicolumn{2}{|c|}{ Model }} & \multicolumn{2}{|c|}{ Unstandardized Coefficients } & \multirow{2}{*}{$\begin{array}{c}\begin{array}{c}\text { Standardized } \\
\text { Coefficients }\end{array} \\
\text { Beta }\end{array}$} \\
\hline & & B & Std. Error & \\
\hline \multirow{3}{*}{1} & (Constant) & -14.057 & 5.801 & \\
\hline & CR & .049 & .008 & .942 \\
\hline & DAR & .292 & .206 & .223 \\
\hline \multicolumn{5}{|c|}{ a. Dependent Variabel: ROA } \\
\hline \multicolumn{5}{|c|}{ Sumber: Output SPSS 20} \\
\hline
\end{tabular}

Berdasarkan tabel 7, persamaan regresi linear berganda pada penelitian ini adalah sebagai berikut:

$\mathrm{ROA}=-14.057+0.049 \mathrm{CR}+0.292 \mathrm{DAR}$ 
Persamaan regresi linear berganda di atas mempunyai konstanta sebesar -14.057 artinya jika ada pengaruh CR dan DAR terhadap ROA, maka nilai ROA akan turun sebesar -14.057

Setiap penambahan angka Current Ratio sebesar 1 akan menambah Return on Asset sebesar 0.049 dan penambahan angka Debt to Asset Ratio sebesar 1 akan menambah Return on Asset sebesar 0.292 .

\section{Uji Koefisiem Determinasi $\left(\mathbf{R}^{2}\right)$}

Uji Koefisien Determinasi dilakukan untuk memprediksi seberapa besar pengaruh variabel independen terhadap variabel dependen. Jika nilai $\mathrm{R}^{2}$ semakin besar maka variabel independen akan semakin berpengaruh terhadap variabel dependen.

Menurut Ghozali 2011: 97 terkait dengan uji koefisien determinasi $\left(\mathrm{R}^{2}\right)$ menjelaskan "Kelemahan penggunaan $\mathrm{R}^{2}$ adalah bias terhadap jumlah variabel independen yang dimasukkan ke dalam model. Oleh karena itu, maka dianjurkan untuk menggunakan nilai adjusted $\mathrm{R}^{2}$ pada saat mengevaluasi mana model regresi terbaik"

\begin{tabular}{|c|c|c|c|c|}
\hline \multicolumn{5}{|c|}{ Tabel 8. Hasil Uji Koefesien Determinasi } \\
\hline Model & $\mathbf{R}$ & R Square & $\begin{array}{l}\text { Adjusted R } \\
\text { Square }\end{array}$ & $\begin{array}{l}\text { Std. Error of the } \\
\text { Estimate }\end{array}$ \\
\hline 1 & $.926^{\mathrm{a}}$ & .857 & .810 & 2.74157 \\
\hline
\end{tabular}

Dari hasil pengujian $\mathrm{R}^{2}$ seperti yang terlihat pada tabel 8. Di atas, diperoleh nilai $\mathrm{R}^{2}$ sebesar 0.857 . Nilai $R$ Square 0.857 ini berasal dari pengkuadratan nilai koefisien korelasi atau " $R$ ", yaitu $0.926 \times 0.926$. Dari angka tersebut dapat disimpulkan bahwa variabel independen Current Ratio dan Debt to Asset Ratio berpengaruh terhadap variabel Return on Asset sebesar 85,7\% sedangkan sisanya dipengaruhi oleh variabel lain diluar kedua variabel tersebut yang tidak diteliti dalam penelitian ini. Hal ini diperkuat dengan nilai Adjusted $\mathrm{R}^{2}$ diperoleh hasil sebesar 0.810 .

\section{Uji Parsial (Uji t)}

Uji t yang dilakukan dalam penelitian ini bertujuan untuk melihat seberapa besar pengaruh variabel independen terhadap variabel dependen secara partial. Pengujian dilakukan dengan membandingkan $\mathrm{t}_{\text {hitung }}$ dengan $\mathrm{t}_{\text {tabel }}$ atau juga dapat dilihat dari nilai signifikansinya. Sebagai acuan dalam membandingkan nilai $t$ atau signifikan dijelaskan sebagai berikut:

- Jika nilai $\mathrm{t}_{\text {hitung }}<\mathrm{t}_{\text {tabel }}$ atau nilai sig. $>0.05$ maka variabel independen $(\mathrm{X})$ tidak berpengaruh terhadap variabel dependen $(\mathrm{Y})$.

- Jika nilai $\mathrm{t}_{\text {hitung }}>\mathrm{t}_{\text {tabel }}$ atau nilai sig. $<0.05$ maka variabel independen $(\mathrm{X})$ berpengaruh terhadap variabel dependen $(\mathrm{Y})$

Dari uji t yang dilakukan dengan SPSS versi 2.0 diperoleh hasil sebagai berikut:

\begin{tabular}{|c|c|c|c|c|c|c|}
\hline \multicolumn{7}{|c|}{ Tabel 9. Hasil Uji Parsial (Uji t) } \\
\hline \multirow{2}{*}{\multicolumn{2}{|c|}{ Model }} & \multicolumn{2}{|c|}{$\begin{array}{l}\text { Unstandardized } \\
\text { Coefficients }\end{array}$} & \multirow{3}{*}{$\begin{array}{c}\begin{array}{c}\text { Standardized } \\
\text { Coefficients }\end{array} \\
\text { Beta }\end{array}$} & \multirow{3}{*}{$\begin{array}{c}\mathbf{t} \\
-2.423\end{array}$} & \multirow{3}{*}{$\begin{array}{l}\text { Sig. } \\
.052\end{array}$} \\
\hline & & \multirow{2}{*}{$\begin{array}{c}\text { B } \\
-14.057 \\
\end{array}$} & \multirow{2}{*}{$\begin{array}{c}\begin{array}{c}\text { Std. } \\
\text { Error }\end{array} \\
5.801\end{array}$} & & & \\
\hline \multirow{3}{*}{1} & (Constant) & & & & & \\
\hline & CR & .049 & .008 & .942 & 5.996 & .001 \\
\hline & DAR & .292 & .206 & .223 & 1.420 & .205 \\
\hline \multicolumn{7}{|c|}{ a. Dependent Variabel: ROA } \\
\hline \multicolumn{7}{|c|}{ Sumber: Output SPSS 20} \\
\hline
\end{tabular}

Berdasarkan hasil analisis $\mathrm{t}_{\text {tabel }}$ di atas maka dapat disimpulkan bahwa untuk melihat pengaruh Current Ratio terhadap Return on Asset maka diperlukan pengujian statistik secara parsial dengan langkah-langkah sebagai berikut :

\section{Merumuskan hipotesis statistik}

Ho: $\beta_{1}=0$ : Menunjukkan bahwa Current Ratio secara parsial tidak berpengaruh terhadap variabel Return on Asset pada PT. Indocement Tunggal Prakarsa Tbk.

Ha: $\beta_{1} \neq 0$ : Menunjukkan bahwa Current Ratio secara parsial berpengaruh terhadap Return on Asset kerja pada PT. Indocement Tunggal Prakarsa Tbk.

\section{Menentukan tingkat signifikasi}

Tingkat a yang digunakan dalam penelitian ini adalah 0,05 atau $5 \%$ yang akan dibandingkan dengan nilai sig pada tabel 9. Sedangkan untuk mencari nilai $\mathrm{t}_{\text {tabel }}$ dengan derajat kebebasan $(\mathrm{df}=$ $\mathrm{n}-\mathrm{k}-1) \mathrm{df}=10-2-1=7$ untuk pengujian dua arah sebesar 2.364 . 
Berdasarkan acuan di atas maka diperoleh hasil perbandingan $\mathrm{t}_{\text {hitung }}$ lebih besar dari $\mathrm{t}_{\text {tabel }}$ yaitu $5.996>2.364$ dan nilai sig lebih kecil dari 0.05 yaitu $0.001<0.05$, sehingga H0 ditolak yang berarti variabel Current Ratio secara parsial berpengaruh signifikan terhadap Return on Asset.

Selanjutnya dilakukan pengujian dan perbandingan yang sama, untuk menguji pengaruh Debt to Asset Ratio terhadap Return on Asset maka diperlukan pengujian statistik secara parsial dengan langkah-langkah sebagai berikut:

\section{Merumuskan hipotesis statistik}

Ho: $\beta_{2}=0$ : Menunjukan bahwa Debt to Asset Ratio secara partial tidak berpengaruh terhadap Return on Asset pada PT Indocement Tunggal Prakarsa Tbk.

Ha: $\beta_{2} \neq 0$ : Menunjukkan bahwa Debt to Asset Ratio secara parsial berpengaruh terhadap Retun on Asset pada PT Indocement Tunggal Prakarsa Tbk.

\section{Menentukan tingkat signifikasi}

Tingkat signifikansi tersebut adalah sebesar $\alpha=0,05$ atau $5 \%$ dengan derajat kebebasan $(\mathrm{df}=$ $\mathrm{n}-\mathrm{k}-1) \mathrm{df}=10-2-1=7$, dimana nilai $\mathrm{t}_{\text {tabel }}$ pengujian dua arah sebesar 2.364.

Hasil yang diperoleh dari perbandingan $\mathrm{t}_{\text {hitung }}$ lebih kecil dari $\mathrm{t}_{\text {tabel }}$ yaitu $1.420<2.364$ dan nilai sig lebih kecil dari 0.05 yaitu $0.205>0.05$, sehingga H0 diterima yang berarti variabel Debt to Asset Ratio secara parsial tidak berpengaruh signifikan terhadap Return on Asset.

\section{Uji F (Uji Simultan)}

Melalui uji $\mathrm{F}$ diperoleh informasi, apakah kedua variabel independen Current Ratio, Debt to Asset Ratio berpengaruh terhadap variabel dependen Return On Asset secara simultan. Pengujian dilakukan dapat dilihat pada uji Anova yang dilakukan dengan pengolahan SPSS.20 dengan menggunakan acuan sebagai berikut:

- Jika nilai $\mathrm{F}_{\text {hitung }}<\mathrm{F}_{\text {tabel }}$ atau nilai sig. $>0.05$ maka variabel independen $(\mathrm{X})$ tidak berpengaruh terhadap variabel dependen $(\mathrm{Y})$

- Jika nilai $\mathrm{F}_{\text {hitung }}>\mathrm{F}_{\text {tabel }}$ atau nilai sig. $<0.05$ maka variabel independen (X) berpengaruh terhadap variabel dependen $(\mathrm{Y})$

\begin{tabular}{|c|c|c|c|c|c|c|}
\hline \multicolumn{7}{|c|}{ Tabel 10. Hasil Uji F } \\
\hline & \multicolumn{6}{|c|}{ ANOVA $^{2}$} \\
\hline \multicolumn{2}{|c|}{ Model } & $\begin{array}{c}\text { Sum of } \\
\text { Squares }\end{array}$ & Df & $\begin{array}{c}\text { Mean } \\
\text { Square }\end{array}$ & $F$ & Sig. \\
\hline \multirow{3}{*}{1} & Regression & 270.851 & 2 & 135.425 & 18.018 & $.003^{b}$ \\
\hline & Residual & 45.097 & 6 & 7.516 & & \\
\hline & Total & 315.948 & 8 & & & \\
\hline \multicolumn{7}{|c|}{$\begin{array}{l}\text { a. Dependent Variabel: ROA } \\
\text { b. Predictors: (Constant), DAR, CR }\end{array}$} \\
\hline
\end{tabular}

Tahapan-tahapan dalam pengujian secara simultan adalah sebagai berikut:

\section{Merumuskan hipotesis statistik}

Ho: $\beta_{1}=\beta_{2}=0$ : Tidak terdapat pengaruh yang signifikan secara simultan dari Current Ratio dan Debt to Asset Ratio terhadap Return on Asset pada PT. Indocement Tunggal Prakarsa. Tbk.

Ha: $\beta_{1} \neq \beta_{2} \neq 0$ : Terdapat pengaruh yang signifikan secara simultan dari Current Ratio Debt to Asset Ratio terhadap Return on Asset pada PT. Indocement Tungal Prakarsa. Tbk.

\section{Menentukan tingkat signifikansi}

Sebelum melalukan perbandingan antara nilai $\mathrm{F}_{\text {hitung }}$ dan $\mathrm{F}_{\text {tabel }}$ maka dilakukan pengambilan data $\mathrm{F}_{\text {tabel }}$ dengan rumus sebagai berikut: $(\mathrm{k} ; \mathrm{n}-\mathrm{k})$ dengan keterangan

$\mathrm{k}=$ jumlah variabel independen (bebas) + jumlah variabel dependen (terikat)

$\mathrm{n}=$ jumlah responden atau sampel penelitian

Data penelitian menunjukkan bahwa $\mathrm{k}=3$ dan $\mathrm{n}=10$ maka angka yang dihasilkan berdasarkan rumus di atas adalah (3; 10-3) sehingga diperoleh nilai $\mathrm{F}_{\text {tabel }}$ dengan df $1=2$ dan df $2=10$ 3-1= 6 sebesar 4.74 .

Angka ini kemudian menjadi acuan untuk mengetahui nilai $\mathrm{F}_{\text {tabel }}$ pada distribusi nilai $\mathrm{F}_{\text {tabel }}$ statistik. Maka diketahui bahwa nilai $\mathrm{F}_{\text {tabel }}$ sebesar 4.74 .

Selanjutnya dilakukan perbandingan pada tabel 10. menunjukkan bahwa $\mathrm{F}_{\text {hitung }}$ sebesar 18.018. Karena $\mathrm{F}_{\text {hitung }}(18.018)>\mathrm{F}_{\text {tabel }}(4.74)$ maka dapat disimpulkan bahwa Ho ditolak dan $\mathrm{Ha}$ diterima, atau dengan kata lain Current Ratio dan Debt to Asset Ratio secara simultan berpengaruh terhadap Return on Asset.

Sedangkan jika berdasarkan Nilai Signifikan 
pada tabel 4.11 di atas, dapat diketahui nilai Sig. sebesar 0.003. Karena nilai signifikansi $0.003<$ 0,05, maka dapat disimpulkan bahwa Ho ditolak dan Ha diterima, dengan kata lain Current Ratio dan Debt to Asset Ratio secara simultan berpengaruh terhadap Return on Asset.

\section{SIMPULAN}

Dari hasil uji t maka Current Ratio berpengaruh secara partial terhadap Return on Asset, namun Debt to Asset Ratio tidak berpengaruh secara partial terhadap Retun On Asset. Dari hasil uji regresi linier berganda diperoleh persamaan $\mathrm{ROA}=-14.057+0.049 \mathrm{CR}+0.292 \mathrm{DAR}$ maka kenaikan Current Ratio dan Debt to Asset Ratio akan menaikkan Return on Asset. Anomali untuk Debt to Asset Ratio semakin tinggi malah akan membuat Return on Asset semakin tinggi walaupun berdasarkan uji t diperoleh hasil tidak ada pengaruh signifikan Debt to Asset Ratio terhadap Return on Asset, kemungkinan disebabkan hutang yang ada digunakan untuk membeli aset atau investasi yang pada akhirnya dapat meningkatkan Return on Asset.

Dari hasil uji F maka Current Ratio dan Debt to Asset Ratio berpengaruh secara simultan terhadap Return on Asset dan hal ini diperlukan dari nilai $\mathrm{R}$ Adjusted ratio sebesar $81 \%$ sehingga kedua variabel tersebut Current Ratio dan Debt to Asset Ratio dapat diasumsikan berpengaruh terhadap Return On Asset sebesar 81\% sisanya sebsar 19\% dipengaruhi variabel lain. Maka disarankan agar perusahaan tetap mempertahankan strategi dalam mengelola aset lancar dan perusahaan dapat menurunkan tingkat pembelian aset dengan menggunakan hutang, yang dapat menyebabkan menurunnya laba perusahaan.

Dari faktor makro jika kondisi perekonomian semakin baik dan penguatan rupiah yang baik dapat mendorong peningkatan penjualan semen PT Indocement Tunggal Prakarsa Tbk. Karena kedua faktor tersebut akan berpengaruh pada pertumbuhan bisnis properti dan stabilnya harga batu bara sebagai salah satu bahan baku semen sehingga secara tidak langsung dapat berdampak pada pendapatan.

\section{PENGHARGAAN}

Penelitian ini bisa berjalan berkat tema teman dan staf perusahaan yang telah memberikan banyak bantuan.

\section{DAFTAR PUSTAKA}

Alpi, M.F. \& Gunawan, A. (2018). Pengaruh Current Ratio dan Total Assets Turnover terhadap Return on Assets Pada Perusahaan Plastik dan Kemasan. Jurnal Riset Akuntasi Aksioma, Vol. 17, No. 2, Desember 2018.

Hanafi, M dan A. Halim. (2016). Analisis Laporan Keuangan. Edisi Kedua. Cetakan Kelima. Yogyakarta: UPP-AMP YKPN

Harahap, S. S. (2015). Analisis Kritis atas Laporan Keuangan. Jakarta: PT Raja Grafindo Persada Harjito, A. \& Martono. (2012). Manajemen Keuangan. Edisi Kedua. Yogyakarta: Ekonisia.

Hery. (2017). Analisis Kinerja Manajemen. Jakarta: PT Grasindo.

Kasmir. (2017). Analisis Laporan Keuangan. Edisi Pertama, Cetakan Kesepuluh Jakarta: PT Rajawali Pers.

Meriana, K. (2013). Pengaruh Debt to Asset Ratio, Current Ratio dan Inventory Turnover Ratio terhadap Return On Assets pada Perusahaan Manufaktur yang terdapat di BEI Periode 2009-2012. Jurnal Akuntansi ISSN: 100462201108.

Munawir. (2010). Analisis Laporan Keuangan. Yogyakarta: Liberty

Octovian, R. (2017). PEMBENTUKAN PORTOFOLIO OPTIMAL (STUDI KASUS INDEKS SAHAM LQ45, BISNIS-27 DAN IDX30 PERIODE. Jurnal Sekuritas, 1(2), 74.

Sartono, A. (2011). Manajemen Keuangan Teori dan Aplikasi. Edisi Keempat. Yogyakarta: BPFE.

Setiawan, I. A. (2013). Analisis Rasio Keuangan untuk Mengukur Kinerja Keuangan PT. Indocement Tunggal Prakarsa Tbk Sebelum dan Sesudah Akuisisi Periode 2007-2011. Jurnal Administrasi Bisnis, 2(1), 74-83.

Sugiyono. (2016). Metode Penelitian Kuantitatif, Kualitatif dan R\&D. Bandung: Alfabeta.

Supardi, H. dkk. (2016). Pengaruh Current Ratio, 
Debt to Asset Ratio, Total asset Turnover dan Inflasi Terhadap Return on Asset pada KOPKAR Indonesia. Jurnal Akuntansi ISSN: 2502-4159.

Thoyib, M., Firman, F., Amri, D., Wahyudi, R., \& Melin, M. A. (2018). PENGARUH CURRENT RATIO, DEBT TO ASSET RATIO, DEBT TO EQUITY RATIO DAN TOTAL ASSET TURNOVER TERHADAP RETURN ON ASSETS PADA PERUSAHAAN ROPERTI DAN REAL ESTATE DI BURSA EFEK INDONESIA. Akuntanika, 4(2), 10-23.
Wartono, T. (2018). Pengaruh Current Ratio (CR) Dan Debt to Equity Ratio (DER) Terhadap Return on Asset (ROA) (Studi Pada Pt Astra International, Tbk). KREATIF: Jurnal Ilmiah Prodi Manajemen Universitas Pamulang, 6(2), 78-97.

Widodo, A. (2018). Analisis Pengaruh Current Ratio (CR), Total Asset Turnover (TATO), Dan Debt to Asset Ratio (DAR) Terhadap Return on Asset (ROA), Serta Dampaknya Terhadap Nilai Perusahaan. JIMF (Jurnal Ilmiah Manajemen Forkamma), 1(2). 